\title{
Peran Orang Tua Terhadap Perilaku Perawatan Gigi Pada Anak Usia Sekolah (6-12 Tahun) Di Dusun Paok Odang Desa Sisik Kecamatan Pringgarata Kabupaten Lombok Tengah
}

\author{
Suswinda Yuli Sutomo ${ }^{1)^{*}}$, Arip Usman ${ }^{2)}$, Vera Yulandasari ${ }^{1)}$, Deasi Wikandari ${ }^{3)}$ \\ Email: suswindayulisutomo@gmail.com \\ 1) Prodi Keperawatan Universitas Qamarul Huda Badaruddin Bagu \\ ${ }^{2)}$ Pasca Sarjana Administrasi Kesehatan, Universitas Qamarul Huda Badaruddin Bagu \\ ${ }^{3)}$ Prodi DIII Farmasi Universitas Qamarul Huda Badaruddin Bagu
}

\begin{abstract}
ABSTRAK
Angka kejadian penyakit gigi dan mulut di Indonesia masih tinggi yaitu sekitar 89\%. Faktor yang mempengaruhi tingginya penyakit gigi adalah perilaku perawatan gigi. Perilaku perawatan gigi banyak dipengaruhi oleh beberapa faktor, salah satunya adalah peran orang tua. Untuk mengetahui hubungan antara peran orang tua terhadap perilaku perawatan gigi pada anak usia sekolah (6-12 tahun). Penelitian ini menggunakan observasi analitik dengan pendekatan cross sectional. Populasi pada penelitian ini berjumlah 71 responden. Sampelnya Orang tua yang memiliki anak usia sekolah (6-12 tahun) sebanyak 71 responden. Tekhnik sampling yang digunakan adalah Total Sampling. Analisa data menggunakan analisa bivariat menggunakan uji Spearman Rank. Sebagian besar peran orang tua cukup baik yaitu sebanyak $43(60,5 \%)$, dan perilaku perawatan gigi anak cukup baik sebanyak $35(49,3 \%)$ hasil Uji statistic Spearman Rank di peroleh nilai korelasi $\pi=0,000$ dengan $p$-value $(0,548)<\alpha(0,05)$, (Ho ditolak). Ada hubungan peran orang tua terhadap perilaku perawatan gigi pada anak usia sekolah (6-12 tahun) dengan kekuatan hubungan sedang. Hal ini berarti semakin baik peran orang tua dalam membimbing anak maka semakin baik pula perilaku perawatan gigi pada anak. Berdasarkan hasil penelitian tersebut disarankan kepada orang tua untuk lebih meningkatkan perannya terhadap perilaku perawatan gigi anak.
\end{abstract}

Kata kunci: Peran orang tua, Perilaku perawatan gigi, anak usia sekolah

\begin{abstract}
Teeth and mouth disease incidence amount of Indonesia is still high, it is around $89 \%$. The factor influencing the high of teeth disease is behavior of teeth care. Behavior of teeth care is influenced by many factors, one of them is the role of parent. The purpose of this research is to identify the correlation between the role of parent and behavior of teeth care on school aged children (6-12 years old). This research design was descriptive correlation with cross sectional approach. The population was all of object in the research as many as 71 respondents. Sample of this research was the parent who have school aged children (6-12 years old) namely 71 respondents and sampling technique used Total sampling. Data analysis using bivariate analysis using Spearman Rank test. Result of research shows the most of parent's role in sufficient category as many as $43(60.5 \%)$, and most of children's teeth care behaviour is in sufficient category $35(49.3 \%)$. Result of data analysis by Spearman Rank test is obtained correlation-value $\tau=0.000$ with pvalue $(0.548)<\alpha(0.05)$ ( Ho was rejected). there is correlation between the role of parent and behavior of teeth care on school aged children (6-12 years old) with moderate relationship strength. It means the better the role of parents in guiding the children's the better the behavior of dental care in children. Based on result of the research, it is suggested to parent to increase their role to ward behavior of teeth care of children.
\end{abstract}

Keywords: role of parent, behavior of teeth care, school aged children 


\section{A. LATAR BELAKANG}

Kesehatan adalah hak asasi manusia dan sekaligus intervensi untuk keberhasilan pembangunan bangsa. Masalah kesehatan anak merupakan salah satu masalah utama dalam bidang kesehatan yang saat ini terjadi di negara Indonesia. Drajat kesehatan anak mencerminkan drajat kesehatan bangsa, sebab anak sebagai generasi penerus bangsa memiliki kemampuan yang dapat dikembangkan dalam meneruskan pembangunan bangsa[1].

Kesehatan gigi dan mulut merupakan bagian dari kesehatan tubuh yang tidak dapat dipisahkan satu dengan yang lainnya, sebab kesehatan gigi dan mulut akan mempengaruhi kesehatan tubuh. Peranan rongga mulut sangat besar bagi kesehatan dan kesejahteraan manusia. Seseorang dikatakan sehat bukan hanya karena tubuhnya yang sehat melainkan juga sehat rongga mulut dan giginya, oleh karena itu kesehatan gigi dan mulut sangat berperan dalam menunjang kesehatan tubuh seseorang [2].

Batasan usia sekolah menurut World Health Organization (WHO) adalah anak yang berusia 6-12 tahun. Penyakit dan kelainan gigi pada anak usia sekolah merupakan salah satu gangguan dalam proses pertumbuhan dan perkembangan anak. Umumnya anak-anak memasuki usia sekolah mempunyai resiko karies yang tinggi, karena pada usia sekolah ini anakanak biasanya suka jajan makan dan minuman sesuai keinginannya[3].

Penyakit gigi dan mulut sejauh ini menjadi masalah kesehatan anak yang memerlukan perhatian. Organisasi Kesehatan Dunia (WHO) pada tahun 2003 menyatakan angka kejadian karies dan penyakit periondontal (radang jaringan pendukung gigi) pada anak masih sebesar 60-90\%. Demikian halnya dengan permasalahan negara Indonesia yang berkaitan dengan kesehatan gigi, terdapat $89 \%$ anak dengan usia di bawah 12 tahun menderita penyakit yang berhubungan dengan gigi dan mulut [4]

Menurut data dari Pengurus Besar PDGI (Persatuan Dokter Gigi Indonesia) menyebutkan bahwa sedikitnya $89 \%$ penderita gigi berlubang adalah anak-anak usia sekolah di bawah 12 tahun sehingga anak usia sekolah dasar merupakan salah satu kelompok yang sangat rentan terhadap penyakit gigi terutama karies dan radang gusi[4]. Berdasarkan hasil data Riset Kesehatan Dasar (Riskesdas) tahun 2013, yang bermasalah gigi dan mulut di Kabupaten Lombok Tengah sebesar 248.041 orang, sedangkan prevalensi penduduk berdasarkan kelompok umur dengan masalah gigi dan mulut usia 5-9 tahun sebesar 25.777 orang dan usia 10-14 tahun sebesar 21.378 orang [5]

Berdasarkan data dari Dinas kesehatan Kabupaten Lombok Tengah tahun 2019, menunjukkan sebesar 6.859 anak SD mengalami masalah pada kesehatan gigi dan mulut, rekapitulasi hasil penjaringan kesehatan gigi peserta didik di wilayah puskesmas bagu menunjukkan data dari 392 siswa yang mengalami gigi berlubang sebesar $278(35,73 \%)$ siswa, gigi kotor $260(33,41 \%)$ siswa, gigi hilang $42(5,39 \%)$ siswa, sisa akar gigi $134(17,22 \%)$ siswa dan peristensi gigi sebesar $64(8,22 \%)$ siswa [6].

Hasil survey pendataan kesehatan masyarakat pada bulan November tahun 2019 di dusun paok odang desa sisik distribusi kondisi gigi anak umur 6-12 tahun yang mengalami gigi hitam dan berlubang sebesar 19 (34,54\%) anak.

Faktor yang mempengaruhi terjadinya masalah gigi antara lain bentuk gigi yang tidak beraturan dan air ludah yang banyak dan kental, adanya bakteri di rongga mulut seperti Streptococus dan Lactobacillus, mengkonsumsi makanan kariogenik (mengandung bahan pewarna, bahan pemanis, bahan pengawet), cara makan seperti makan atau minum panas dan dingin secara bersamaan atau dalam rentang waktu yang singkat, kebiasaan menjaga kebersihan gigi dan mulut masih kurang[7]

Perilaku pola makan yang demikian sangat berpengaruh terhadap kejadian karies gigi anak dan di pengaruhi pula dengan tingkat pengetahuan anak tentang menggosok gigi yang baik dan benar, ada hubungan yang bermakna 
antara perilaku menggosok gigi dengan kejadian karies gigi pada anak[8]

Kebiasaan buruk pada anak juga mempengaruhi terjadinya masalah gigi, diantaranya adalah kebiasaan menghisap jari atau ibu jari, menahan (ngemut) makanan dalam mulut, menggigit-gigit kuku, pensil, tusuk gigi, jepit rambut, memotong benang, bruxism (mengerot, menggigit-gigitkan gigi atas dan bawah pada waktu tidur) serta menyikat gigi sangat kuat dengan gerakan horisontal. Beberapa faktor ini bisa dilakukan perawatan gigi[9].

Motivasi mempunyai pengaruh paling besar terhadap pemeliharaan kesehatan gigi dan mulut, semakin baik persepsi dan semakin kuat motivasi maka semakin baik perilaku anak dalam menjaga kesehatan gigi dan mulutnya[10].

Perawatan gigi sedini mungkin akan mencegah gigi berlubang dan gusi menjadi sehat sehingga anak tidak merasakan sakit gigi, mencegah gigi sulung dicabut sebelum waktunya tanggal karena gigi busuk (gangren).

Pendidikan kesehatan gigi harus diperkenalkan sedini mungkin kepada anak agar mereka dapat mengetahui cara memelihara kesehatan gigi dan mulut secara baik dan benar[11]

Anjuran pokok perawatan gigi ada 4 yaitu, pertama, sikat gigi 2 kali sehari dengan pasta gigi ber-flouride, terutama sesudah makan pagi dan sebelum tidur. Menggosok gigi setelah makan bertujuan mengangkat sisa-sisa makanan yang menempel dipermukaan atau sela-sela gigi dan gusi, sedangkan menggosok gigi sebelum tidur berguna untuk menahan perkembangbiakan bakteri dalam mulut karena dalam keadaan tidur tidak diproduksi ludah yang berfungsi membersihkan gigi dan mulut secara alami, mengosok gigi dengan pasta gigi ber-fluoride berfungsi untuk melindungi gigi dari kerusakan dengan cara mengganti mineral-mineral gigi yang hilang akibat erosi dari asam, anjuran perawatan gigi di atas, jika tidak diperhatikan dengan baik, maka akan menyebabkan beberapa gangguan pada gigi dan mulut antara lain adalah anak akan terserang karies gigi, penyakit periondontal (gingivitis dan periodontitis), pulpitis, pembengkakan pada sekitar gigi dan wajah, trauma pada gigi sulung, persistensi dan gigi sulung yang goyang, halitosis, stomatitis, maloklusi, diskolorasi, dan abses periapikal[11].

Keluarga merupakan kelompok sosial kecil yang terdiri dari suami, istri beserta anakanaknya. Keluarga juga merupakan lingkungan yang pertama dan utama bagi pembentukan kepribadian anak. Ibu merupakan orang yang pertama kali dijumpai seorang anak dalam kehidupannya, karena itu segala perilaku, cara mendidik anak, dan kebiasaannya dapat dijadikan contoh bagi anaknya. Selain itu, kedekatan fisik antara orang tua dengan anak, biasanya menampilkan sikap ketergantungan anak sehingga perilaku anak sangat dipengaruhi oleh perilaku orang tua. Hal ini menjadi dasar keyakinan para ahli bahwa tingginya angka penyakit gigi pada anak sangat dipengaruhi oleh peran orang tua, khususnya ibu. Apabila perilaku orang tua mengenai kesehatan gigi baik, maka dapat dilihat bahwa status kesehatan gigi dan mulut anaknya akan baik[12]

Peran ibu dalam upaya meningkatkan kesehatan gigi dan mulut anak dapat dilihat dari sikap dan perhatiannya terhadap perawatan gigi dan mulut anaknya. Hal ini membutuhkan waktu, kemauan, dan kemampuan dari orang tua untuk mengajarkan kepada anak. Peran serta orang tua adalah membimbing, memberikan pengertian, memberi contoh, mengingatkan dan menyediakan fasilitas bagi anak agar anak dapat memelihara kebersihan gigi dan mulutnya[13].

Berdasarkan hal tersebut peneliti tertarik untuk meneliti tentang Hubungan Peran Orang Tua Terhadap Perilaku Perawatan Gigi Pada Anak Usia Sekolah (6-12 Tahun) Di Dusun Paok Odang Desa Sisik Kecamatan Pringgarata Kabupaten Lombok Tengah

\section{B. METODE PENELITIAN}

Desain penelitian merupakan rencana penelitian yang disusun sedemikian rupa sehingga peneliti dapat memperoleh jawaban terhadap pertanyaan penelitian[14] 
Penelitian ini menggunakan desain penelitian observasi Analitik dengan menggunakan pendekatan cross sectional. Penelitian dengan menggunakan pengukuran atau pengamatan pada variabel independen dan variabel dependen secara bersamaan atau sekali waktu antara faktor resiko dengan efek. Pada penelitian ini peneliti akan melakukan pengukuran pada variabel dependen dan independen sekaligus dalam waktu yang bersamaan dan pada saat itu juga hasil pengukuran di dapat secara bersamaan [15].

Metode penelitian ini digunakan untuk mengetahui hubungan antara peran orang tua terhadap perilaku perawatan gigi pada anak usia sekolah (6-12 tahun) di Dusun Paok Odang Desa Sisik Kecamatan Pringgerata Kabupaten Lombok Tengah.

\section{HASIL DAN PEMBAHASAN}

1. Peran Orang Tua Pada Anak Usia Sekolah (6-12 Tahun)

\begin{tabular}{|c|c|c|c|}
\hline No & Penilaian & Frekuensi & Persentase \\
\hline 1 & Baik & 19 & $26,8 \%$ \\
\hline 2 & Cukup Baik & 33 & $46,5 \%$ \\
\hline \multirow[t]{2}{*}{3} & Kurang Baik & 19 & $26,8 \%$ \\
\hline & Tota & 75 & $100 \%$ \\
\hline
\end{tabular}

Sumber Data primer

Berdasarkan tabel diatas menunjukkan bahwa sebagian besar peran orang tua cukup baik yaitu sejumlah 33 orang (46,5\%). Sedangkan frekuensi terendah yaitu responden dengan Peran orang tua kurang baik dan baik yaitu sebanyak 19 orang $(26,8 \%)$.

Penelitian yang telah dilakukan oleh Husna, A. [16] mengemukakan bahwa sebagian besar orang tua dalam kategori cukuf aktif, artinya semakin aktif peranan orang tua maka akan semakin baik pula perilaku anak.

Menurut asumsi peneliti orang tua tidak hanya berperan melainkan bertindak atau memberikan contoh langsung pada anaknya karena dengan tindakan akan mempengaruhi status kesehatan gigi anak, contohnya orang tua memberikan contoh dan mengajak anak untuk menggosok gigi sebelum tidur. Hal ini diperkuat dengan pendapat Riyanti, E[17] bahwa peranan orang tua sangat penting dalam membimbing, memberikan pengertian, mengingatkan, dan member teladan sehingga anak mampu mengembangkan pertumbuhan pribadinya.

Dalam penelitian ini, peran orang tua dalam perilaku perawatan gigi anak dapat dipengaruhi oleh beberapa faktor seperti faktor pendidikan, pengetahuan, umur, pekerjaan dan jenis kelamin. Orang tua yang pekerjaannya seorang Ibu Rumah Tangga akan lebih lama dan sering bersama anaknya, pada saat inilah orang tua bermain peran untuk menjaga perilaku anak dalam perawatan gigi baik dari perannya sebagai teladan, membimbing, menyediakan fasilitas dan sebagainya.

2. Perilaku Perawatan Gigi Pada Anak Usia Sekolah (6-12 Tahun)

\begin{tabular}{|c|c|c|c|}
\hline No & Penilaian & Frekuensi & Persentase \\
\hline 1 & Baik & 25 & $35,2 \%$ \\
\hline 2 & Cukup Baik & 35 & $49,3 \%$ \\
\hline 3 & Kurang Baik & 11 & $15,5 \%$ \\
\hline & Total & 75 & $100 \%$ \\
\hline
\end{tabular}

Sumber Data primer

Berdasarkan tabel diatas menunjukkan bahwa sebagian besar perilaku perawatan gigi pada anak usia sekolah (6-12 tahun) dalam kategori cukup baik, yaitu sejumlah 35 orang $(49,3 \%)$. Sedangkan frekuensi terendah dalam kategori kurang baik yaitu sebanyak 11 responden $(15,5 \%)$.

Perilaku manusia adalah semua tindakan atau aktivitas dari manusia itu sendiri, baik yang dapat diamati, kemudian perilaku ini dapat terjadi adanya stimulus dari manusia, dan kemudian manusia tersebut akan memberikan respon [18].

Menurut asumsi peneliti Kesadaran individu terhadap kebersihan gigi akan berpengaruh terhadap kesehatan gigi orang tersebut, dimana pada anak usia sekolah belum memiliki kesadaran akan kebersihan giginya sehingga dalam hal ini anak memerlukan arahan atau bantuan dari orang tuanya terutama ibu untuk menumbuhkan kesadaran dari anak tentang kebersihan gigi seperti orang tua menjelaskan 
macam-macam penyakit yang akan timbul jika tidak memperhatikan kebersihan giginya, seperti karies, perubahan warna gigi, bau mulut, dan sebagainya.

Kebersihan mulut sangat ditentukan oleh perilaku personal. Pemeliharaan hygiene mulut yang tidak benar menyebabkan mudahnya penumpukan plak, material alba dan kalkulus yang pada akhirnya akan merugikan kesehatan periodontal[19].

Menurut peneliti Perilaku perawatan gigi yang baik lebih banyak terjadi pada anak dengan peran orang tua baik, oleh karena itu peran orang tua sangat berperan penting dalam perilaku anak, dimana pada penelitian ini diperoleh hasil peran orang tua cukup baik dengan perilaku perawatan gigi anak cukup baik.

\section{Hubungan Peran Orang Tua Terhadap Perilaku Perawatan Gigi pada Anak Usia Sekolah (6-12 tahun) Di Dusun Paok Odang Desa Sisik Kecamatan Pringgarata Kabupaten Lombok Tengah

\begin{tabular}{|c|c|c|c|c|c|c|c|c|c|c|}
\hline \multirow{3}{*}{$\begin{array}{c}\text { Peran } \\
\text { Orang } \\
\text { Tua }\end{array}$} & \multicolumn{6}{|c|}{ Perilaku Perawatan Gigi } & \multicolumn{2}{|c|}{ Total } & \multirow{3}{*}{$\begin{array}{c}\rho \\
\text { value }\end{array}$} & \multirow[t]{2}{*}{$\mathrm{r}$} \\
\hline & \multicolumn{2}{|c|}{ Baik } & \multicolumn{2}{|c|}{$\begin{array}{c}\text { Cukup } \\
\text { Baik }\end{array}$} & \multicolumn{2}{|c|}{$\begin{array}{c}\text { Kurang } \\
\text { Baik }\end{array}$} & & & & \\
\hline & $\mathrm{n}$ & $\%$ & $\mathrm{~N}$ & $\%$ & $\mathrm{n}$ & $\%$ & $\mathrm{n}$ & $\%$ & & \\
\hline Baik & 12 & 16,9 & 6 & 8,5 & 1 & 1,4 & 19 & 26,8 & & \\
\hline $\begin{array}{c}\text { Cukup } \\
\text { Baik }\end{array}$ & 11 & 15,5 & 20 & 28,2 & 2 & 2,8 & 33 & 46,4 & 0,000 & 0,548 \\
\hline $\begin{array}{c}\text { Kurang } \\
\text { Baik }\end{array}$ & 2 & 2,8 & 9 & 12,7 & 8 & 11,3 & 19 & 26,8 & & \\
\hline Total & 25 & 35,2 & 35 & 49,3 & 11 & 15,5 & 71 & 100 & & \\
\hline
\end{tabular}

Tabel diatas menunjukkan bahwa perilaku perawatan gigi anak cukup baik dengan peran orang tua cukup baik sebanyak 20 orang $(28,2 \%)$. Sedangkan responden yang perilaku perawatan gigi baik dengan peran orang tua baik sebanyak 12 orang (16,9\%). Hubungan Peran Orang Tua Terhadap Perilaku Perawatan Gigi Pada Anak Usia Sekoalah (6-12 Tahun) di Dusun Paok Odang berdasarkan hasil uji Spearman rank didapatkan hasil $\rho$ value $=0,000<0,05$ maka Ho ditolak dan $\mathrm{Ha}$ diterima sehingga dapat disimpulkan bahwa ada hubungan antara peran orang tua terhadap perilaku perawatan gigi pada anak usia sekolah (6-12 tahun) dengan kekuatan hubungan sedang. Artinya bahwa semakin baik peran orang tua dalam membimbing anak merawat gigi maka semakin baik perilaku perawatan gigi pada anak.

Uji statistik hubungan peran orang tua terhadap perilaku perawatan gigi pada anak usia sekolah (6-12 tahun) di dusun paok odang desa sisik kecamatan pringgarata kabupaten Lombok tengah dengan uji Spearman rank didapatkan hasil $\rho$ value $=0,000<0,05$ maka Ho ditolak dan Ha diterima yang berarti secara statistik dapat disimpulkan ada hubungan antara peran orang tua terhadap perilaku perawatan gigi pada anak usia sekoalah (6-12 tahun) di Dusun Paok Odang Desa Sisik Kecamatan Pringgarata Kabupaten Lombok Tengah.

Perhitungan korelasi koefisien diperoleh hasil 0,548 sehingga kekuatan hubungan antara peran orang tua terhadap perilaku perawatan gigi pada anak usia sekoalah (6-12 tahun) di Dusun Paok Odang Desa Sisik Kecamatan Pringgarata Kabupaten Lombok Tengah adalah kekuatan sedang, Yang artinya jika peran orang tua semakin baik maka perilaku perawatan gigi anak usia sekolah (6-12 tahun) juga akan semakin baik.

Penelitian ini di dukung oleh penelitian Natamiharja[20] yang meneliti hubungan pendidikan, pengetahuan, dan perilaku ibu terhadap status karies balitanya menunjukkan bahwa ada hubungan antara dengan perilaku ibu terhadap status karies balitanya.

Peran orang tua merupakan faktor yang utama dalam melaksanakan perilaku perawatan gigi pada anak. Orang tua sangat besar pengaruhnya terhadap kehidupan anak-anaknya. Sikap orang tua akan dijadikan contoh bagi anakanaknya. Peran yang aktif dari orang tua akan menjadikan anak terbiasa menggosok gigi secara rutin. Faktor yang mempengaruhi peran adalah pendidikan atau tingkat pengetahuan. Keyakinan seseorang terhadap adanya dukungan terbentuk oleh variabel intelektual yang terdiri dari pengetahuan, latar belakang pendidikan, dan pengalaman masa lalu. Kemampuan kognitif akan membentuk cara berfikir seseorang termasuk kemampuan untuk memahami faktor- 
faktor yang berhubungan dengan penyakit dan menggunakan pengetahuan tentang kesehatan untuk menjaga kesehatan dirinya.

Masalah kesehatan gigi pada anak SD perlu diperhatikan agar penyakit karies dapat dicegah secara dini, dalam penelitiannya menunjukkan ada hubungan yang bermakna antara perilaku menggosok gigi dan pola jajan pada anak dengan kejadian karies gigi[21].

Faktor teman sebaya yang ada di lingkungan sekolah, serta tersedianya berbagai jenis jajanan anak-anak di lingkungan sekolah yang pada umumnya bersifat manis, lunak, dan melekat pada gigi seperti permen, coklat dan biscuit, dimana dalam hal ini sangat dibutuhkan peran orang tua dalam mengawasi makanan-makanan yang bisa merusak gigi anak[22].

Pembentukan perilaku anak selain dari pengaruh orang tua, juga dari pengaruh guru di sekolah. Pada saat seorang anak mencapai usia sekolah, guru dapat juga dijadikan sebagai model. Figur tokoh (model) akan berpengaruh pada diri anak, dimana tokoh ibu digantikan dengan tokoh guru pada saat anak di sekolah. Guru memberikan pengetahuan kepada anak dengan disertai latihan cara menyikat gigi, Hal ini sangat baik untuk menanamkan kebiasaan anak agar berdisiplin memelihara kesehatan giginya[23].

Hasil dari penelitian ini menunjukkan bahwa peran orang tua cukup baik, maka perilaku perawatan gigi anak juga cukup baik. Namun, peran orang tua bukan satu-satunya faktor yang berperan tunggal dalam menumbuhkan perilaku perawatan gigi pada anak. Faktor-faktor yang ikut mempengaruhi perilaku perawatan gigi anak, antara lain : lingkungan, budaya, sosial ekonomi, kesadaran akan kesehatan gigi, usia anak, dan hubungan dengan teman sebaya.

Menurut penelitian yang dilakukan rata-rata perilaku perawatan gigi anak menggosok gigi sebelum tidur kurang baik, dan rata-rata peran orang tua untuk membawa anaknya ke dokter gigi 6 bulan sekali tidak dilakukan.

\section{KESIMPULAN}

Peran orang tua di Dusun Paok Odang Desa Sisik Kecamatan Pringgarata Kabupaten Lombok Tengah menunjukkan bahwa sebagian besar dalam kategori cukup baik.

Perilaku perawatan gigi pada anak usia (6-12 tahun) di Dusun Paok Odang Desa Sisik Kecamatan Pringgarata Kabupaten Lombok Tengah menunjukkan bahwa sebagian besar dalam kategori cukup baik.

Dalam penelitian ini Ada hubungan yang signifikan antara peran orang tua terhadap perilaku perawatan gigi pada anak usia (6-12 tahun) di Dusun Paok Odang Desa Sisik Kecamatan Pringgarata Kabupaten Lombok Tengah tahun 2020, Hal ini berarti semakin baik peran orang tua dalam membimbing anak maka semakin baik pula perilaku perawatan gigi pada anak.

\section{UCAPAN TERIMA KASIH}

Pada kesempatan ini, penulis ingin mengucapkan terima kasih kepada berbagai pihak yang telah membantu mewujudkan penelitian ini :

1. Rektor Universitas Qamarul Huda Badaruddin (UNIQHBA) Bagu

2. Prodi S1 Keperawatan

3. Kepala Puskesmas Bagu

\section{DAFTAR PUSTAKA}

[1]. Utami, V. (2017). Hubungan Tingkat Pengetahuan Siswa SD Kelas III Dan IV Tentang Cara Menyikat Gigi Terhadap Kejadian Karies Gigi Di SDN Montong Ara. Stikes Qamarul Huda. Skripsi.

[2]. Andarmoyo, S.,(2012).Personal hygiene konsep teori, proses, dan praktik keperawatan. Yogyakarta : Graha Ilmu

[3]. Worotitjan Indry, Mintjelungan Christy N, \& Gunawan Paulina. (2013). Pengalaman Karies Gigi Serta Pola Makan Dan Minum Pada Anak Sekolah Dasar di Desa Kiawa Kecamatan Kawangkoan Utara.

[4]. Sariningsih, E. (2012). Merawat gigi anak sejak usia dini. Jakarta : Kompas Gramedia. 
[5]. Riset Kesehatan Dasar (2013). Riset Kesehatan Dasar Dalam Angka Prevalensi Status Kesehatan Gigi Dan Mulut. http://www.Riskesdas 2013

[6]. Puskesmas Bagu (2019). Rekapitulasi Hasil Penjaringan Kesehatan Gigi.

[7]. Kusumawardani, E. (2011). Buruknya kesehatan gigi dan mulut. Yogyakarta : SIKLUS Hanggar Kreator.

[8]. Sari, IP. \&Andini, D. (2014). Jurnal Hubungan perilaku menggosok gigi dan pola jajan anak dengan kejadian karies gigi. Di ambil

dari https://www.neliti.com/id/publications/1817 35/hubungan-perilaku-menggosok-gigi-danpola-jajan-anak-dengan-kejadian-karies-gigi

[9]. Sariningsih, E. (2012). Merawat gigi anak sejak usia dini. Jakarta : Kompas Gramedia.

[10]. Pey, MN. \&Widiati, S. (2016).Jurnal identifikasi faktor yang mempengaruhi perilaku anak dalam pemeliharaan $\square$ Identi kebersihan gigi dan mulut: Studi pada Pusat Pengembangan Anak Agape Sikumana Kota Kupang, Nusa Tenggara Timur, Indonesia. Di ambil dari https://jurnal.ugm.ac.id/mkgi/article/downloa d/9900/11421

[11]. Natamiharja L,(2010). Hubungan pendidikan, pengetahuan dan perilaku ibuterhadap status karies gigi balitanya. Dentika Dental J 2010; 15(1) : 38

[12]. Soekanto, S. (2009). Sosiologi keluarga tentang ikhwal keluarga, remaja dan anak. Jakarta: Rineka Cipta

[13]. Simanjuntak, A.D, Dkk. (2014). jurnal Hubungan Peran Orang Tua Dalam Perawatan Gigi Anak Terhadap Resiko Kejadian Karies Pada Anak Usia 6-8 Tahun Di Sekolah Dasar Kelurahan Sungai Beliung Pontianak Tahun 2014Di ambil dari http://jurnal.untan.ac.id/index.php/ jmkeperawatanFK/ article/view/11625 di akses tanggal 18 april 2018

[14]. Setiadi, (2007). Konsep dan Riset Keperawatan. Yogyakarta : Graha Ilmu.

[15]. Notoatmodjo, S. (2010). Metodelogi Penelitian Kesehatan. Jakarta : Rineka Cipta.

[16]. Husna, A. (2015). Peranan Orang Tua Dan Perilaku Anak Dalam Menyikat Gigi Dengan Kejadian Karies Anak. Jurnal Vokasi Kesehatan

[17]. Riyanti, E. (2012). Pengenalan Dan Perawatan Kesehatan Gigi Anak Sejak Dini.
[18]. Notoatmodjo, S. (2012). Ilmu Prilaku Kesehatan. Jakarta : Rineka Cipta.

[19]. Candra, W. (2017). Hubungan Peran Orang Tua Dengan Kejadian Karies Gigi Pada Anak Prasekolah Di TK Karta Rini Godean Sleman Yogyakarta. Sekolah tinggi ilmu kesehatan jendral achmad yani yogyakarta. Skripsi. Diambildari http://repository.unjaya.ac.id/2231/2/WISNU \%20CANDRA\%20FIRMANSYAH 221308 1 pisah.pdf.

[20]. Natamiharja L,(2010). Hubungan pendidikan, pengetahuan dan perilaku ibuterhadap status karies gigi balitanya. Dentika Dental J 2010; 15(1) : 38

[21]. Andini, D. \& Permatasari, I. (2014). Hubungan perilaku menggosok gigi dan pola jajan anak dengamn kejadian karies gigi pada murid SD negeri 157 palembang tahun 2014. Jurnal keperawatan di ambil dari https://www.neliti.com/id/publications/1817 35/hubungan-perilaku-menggosok-gigi-danpola-jajan-anak-dengan-kejadian-karies-gigi

[22]. Notoatmodjo, S. (2007). Promosi kesehatan dan ilmu perilaku. Jakarta : Rineka Cipta.

[23]. Oktorina, R \& Fatimah, S (2012).Jurnal Gambaran Pengetahuan ibu Tentang peranannya Dalam Perawatan Gigi Anak Kelas 1,2,Dan 3. Di ambil dari http://jurnal.unpad.ac.id/ejournal/article/view File/805/851 di akses tanggal 16 april 2018. 